\title{
Correspondence
}

\section{Accelerated onset of rocuronium}

To the Editor:

I read with interest the recent paper by Naguib on the use of priming technique for accelerating the onset of action of rocuronium. ${ }^{1}$

Dr. Naguib is obviously a firm believer in the usefulness of the priming technique. Although we have not tested the priming principle for rocuronium we have not been able to observe any effect on the onset or duration of action of atracurium and vecuronium. ${ }^{2}$ Although Dr. Naguib has correctly quoted an onset time of $88.9 \mathrm{sec}$ reported by us using a $0.6 \mathrm{mg} \cdot \mathrm{kg}^{-1}$ dose of rocuronium, ${ }^{3}$ this was obtained using a single twitch mode of stimulation at $0.1 \mathrm{~Hz}$ compared with the train-of-four (TOF) mode of stimulation used by Dr. Naguib in his study. Using a train-of-four mode of monitoring we were able to attain complete block with a $0.6 \mathrm{mg} \cdot \mathrm{kg}^{-1}$ dose of rocuronium in approximately $60 \mathrm{sec}^{4}$ There are other studies which have shown that using a TOF mode of stimulation results in a faster onset than by using a single twitch mode of stimulation at $0.1 \mathrm{~Hz}$. Dr. Naguib has also suggested that the difference in his results and those of Foldes $e t$ al. ${ }^{5}$ could be due to the use of the different priming doses in the two studies. It is difficult to understand how a priming dose of $0.1 \mathrm{mg} \cdot \mathrm{kg}^{-1}$ would not produce any acceleration in the onset of rocuronium but a dose of $0.06 \mathrm{mg} \cdot \mathrm{kg}^{-1}$ would. It is likely that priming would contribute little to the onset of effect of a rapidacting drug like rocuronium. There is no evidence from Dr. Naguib's study that a three minute interval for priming is more appropriate than a four minute interval.

It is not logical to look at intubating conditions in the various groups when patients are administered a dose of thiopentone immediately before intubation. Dr. Naguib's study has in any case shown no improvement in the intubating conditions by priming. The study of Cooper et al. where no drugs were administered in the five-minute period before intubation showed that intubating conditions with rocuronium were excellent to good at 60-90 seconds and comparable to those of suxamethonium even without any priming.

R.K. Mirakhur MD Phd FRCA FFARCSI

Department of Anaesthetics

The Queen's University of Belfast

\author{
Whitla Medical Building \\ 97 Lisburn Road \\ Belfast BT12 6BA \\ $\mathrm{N}$ Ireland (UK)
}

\section{REFERENCES}

1 Naguib $M$. Different priming techniques, including mivacurium, accelerate the onset of rocuronium. Can J Anaesth 1994; 41: 902-7.

2 Brady MM, Mirakhur RK, Clarke RSJ. Administration of vecuronium, atracurium and pancuronium in divided doses: effect on onset and duration of action. Eur $\mathbf{J}$ Anaesth 1988; 5: 243-9.

3 Cooper AR, Mirakhur RK, Clarke RSJ, Boules Z. Comparison of intubating conditions after administration of ORG 9426 (rocuronium) and suxamethonium. $\mathrm{Br} \mathrm{J}$ Anaesth 1992; 69: 269-73.

4 Cooper $R$, Mirakhur RK, Maddineni VR. Neuromuscular effects of rocuronium (Org 9426) during fentanyl and halothane anaesthesia. Anaesthesia 1993; 48: 103-5.

5 Foldes FF, Nagashima H, Nguyen HD, Schiller WS, Mason MM, Ohta $Y$. The neuromuscular effects of ORG 9426 in patients receiving balanced anesthesia. Anesthesiology 1991; 75: 191-6.

\section{REPLY}

Thank you for the opportunity to comment on the letter of Dr. Mirakhur. I was surprised to know that Dr. Mirakhur is still questioning the efficacy of the priming principle. The literature on priming is very comprehensive and a Medline search revealed 96 citations about the priming principle. Failure of Dr. Mirakhur and his colleagues to observe any acceleration of the onset of atracurium and vecuronium with priming does not mean that we should bury this technique. The precise doses used for priming and the time interval separating them are obviously of crucial importance ${ }^{2-4}$ (see Jones for review). In contrast to $\mathrm{Dr}$. Mirakhur's opinion, different investigators have reported that priming accelerated the onset of neuromuscular blockade induced by atracurium and vecuronium. ${ }^{2-4,6-8}$ Although Dr. Mirakhur reported previously that the duration of clinical relaxation of vecuronium was significantly prolonged by giving it in divided (priming) doses, ${ }^{9}$ we agree with the statement in his letter that priming does not affect the duration of action of atracurium and vecuronium. Considering the above comments and taking into account that rocuronium has a rapid onset of action, it is most likely that the difference in our results ${ }^{10}$ and those of Foldes et al. difference in the size of the priming dose and priming interval. We have also pointed out in the discussion 10 that Foldes et al.," by changing the size of the priming dose and priming interval, noted that priming accelerated the onset of rocuronium in the rat. 